Alaska Division of Geological \& Geophysical Surveys

RAW-DATA FILE 2014-20

LIDAR DATA FOR THE COMMUNITY OF GOLOVIN, ALASKA

by

Lauren E. Southerland and Nicole E.M. Kinsman

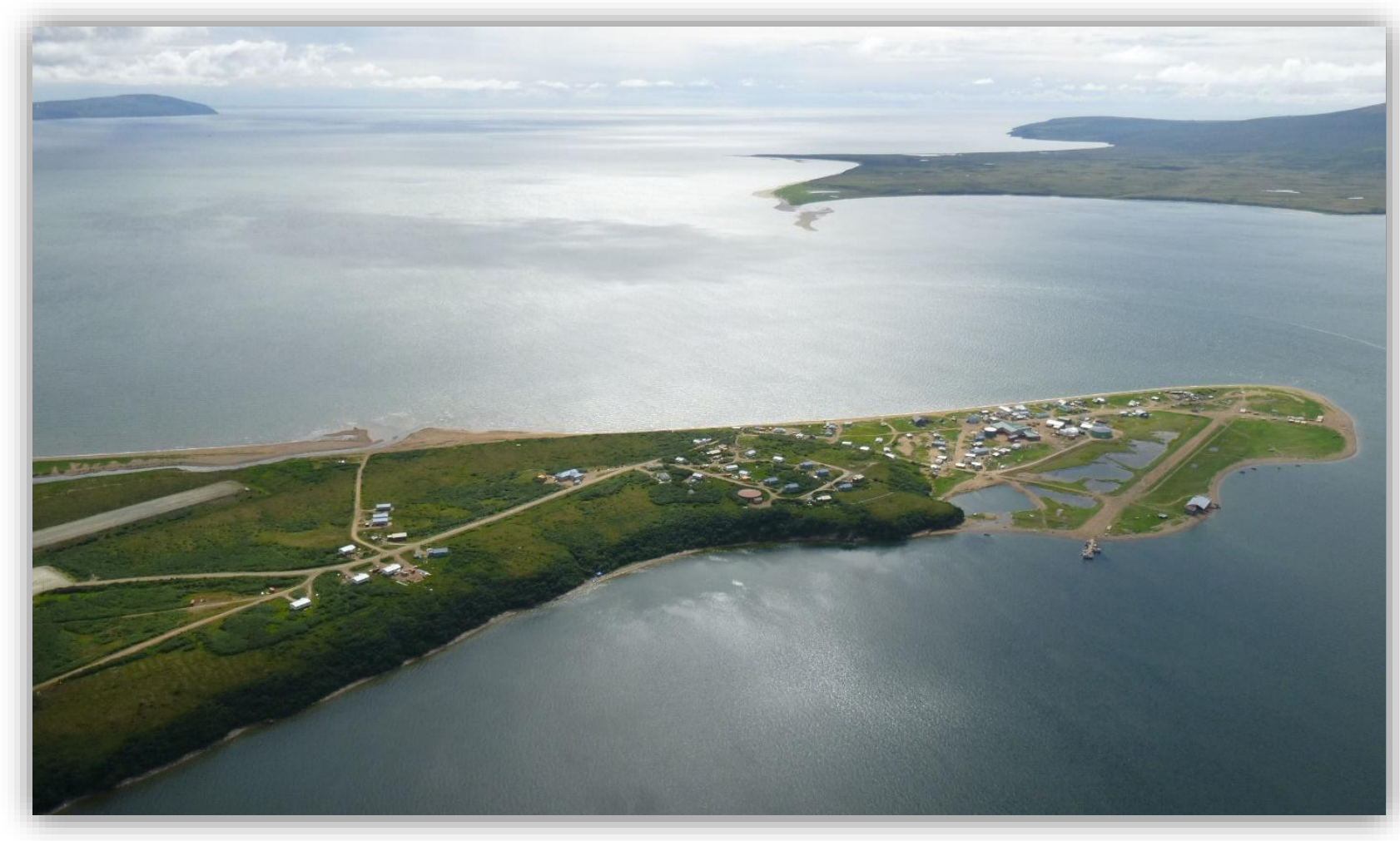

NOVEMBER 2014

Oblique aerial photograph of Golovin in Norton Sound, Alaska, looking south across the peninsula and spit (photo by Nicole Kinsman, 2012)

\title{
Released by:
}

STATE OF ALASKA

DEPARTMENT OF NATURAL RESOURCES

Division of Geological \& Geophysical Surveys

3354 College Road, Fairbanks, Alaska 99709-3707

Email: dggspubs@alaska.gov

Website: www.dggs.alaska.gov 




\section{CONTENTS}

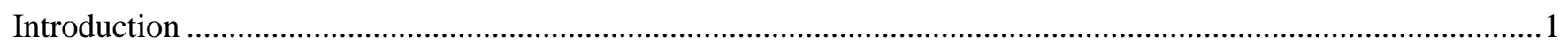

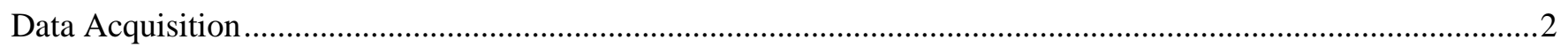

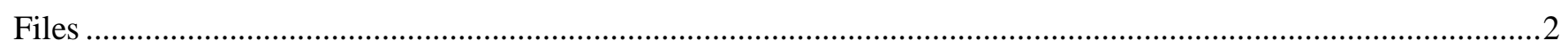

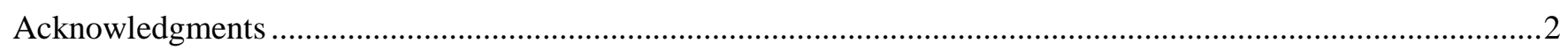

\section{FIGURE}

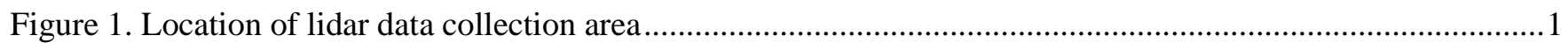

\section{APPENDIX}

Appendix A. Golovin, Alaska, lidar: Technical Data Report (Quantum Spatial, Sept. 19, 2014) 3

Note: This report, including all digital lidar data, explanations, and tables, is available in digital format from the DGGS website (www.dggs.alaska.gov) for free download. 


\title{
LIDAR DATA FOR FOR THE COMMUNITY OF GOLOVIN, ALASKA
}

\author{
by
}

Lauren E. Southerland and Nicole E.M. Kinsman

\section{Introduction}

This report is a summary of lidar data collected over the community of Golovin, on the southern coast of the Seward Peninsula in western Alaska (fig. 1). The original data were collected on November 5, 2013, by Quantum Spatial. The complete, classified lidar dataset was purchased by the State of Alaska Division of Geological \& Geophysical Surveys in 2014 in support of coastal vulnerability mapping efforts. For the purposes of open access to lidar datasets in coastal regions of Alaska, this collection is being released as a Raw Data File with an open end-user license.

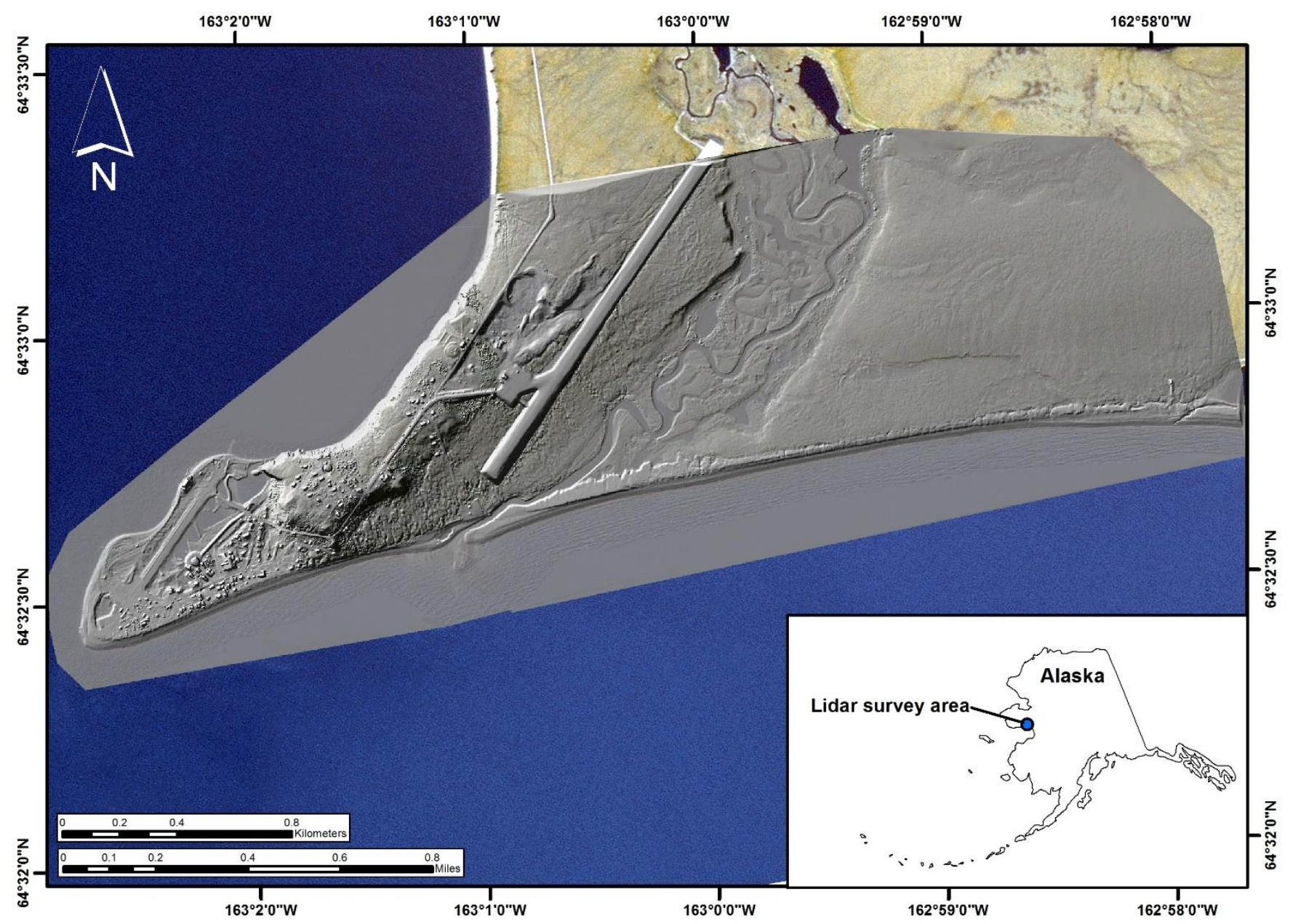

FIGURE 1. Location map of 2013 lidar data collection area over the coastal community of Golovin, Alaska, displayed as a hillshaded raster overlain on 2005 SPOT-5 satellite imagery. 


\section{Data acquisition}

Lidar data, initially collected on November 5, 2013, and fully post-processed in 2013 by Quantum Spatial, comprises a $1.64 \mathrm{mi}^{2}$ coverage over the coastal community of Golovin $\left(64.5447^{\circ} \mathrm{N}, 163.0275^{\circ} \mathrm{W}\right.$, Solomon C-3 and C-2 U.S. Geological Survey quadrangles, scale 1:63,360).

The lidar dataset for this area was obtained with an average laser pulse rate of $70 \mathrm{kHz}$ under operational conditions designed to achieve a nominal point spacing of $0.50 \mathrm{~m}$. The data were delivered to DGGS with a reported vertical accuracy of $0.107 \mathrm{~m}$ at the 95 percent confidence interval. This confidence value is based on 15 check points provided by DGGS and evaluated by Quantum Spatial; a full summary of this vertical accuracy assessment is available in the 2014 delivery report, which can be found on the DGGS website (doi:10.14509/29127).

The vertical accuracy of the lidar dataset was independently evaluated by DGGS using control points $(n=10)$ that were collected by DGGS during the course of 2012 fieldwork. The standard deviation of the differences between these independent control points and the lidar point-cloud data confirmed the vertical accuracy reported by Quantum Spatial in the 2014 delivery report.

The 2014 delivery report also contains an explanation of the point-cloud classification scheme that was applied by Quantum Spatial.

\section{Files}

The project files available for download comprise tiled and classified lidar point-clouds (LAS 1.2 format), polygons for the tile index, and a polygon that outlines the full lidar survey area. These data are projected in UTM Zone 3 (meters) using the NAD83 horizontal and NAVD88 (Geoid12A) vertical datums, as outlined in the accompanying metadata.

\section{Acknowledgments}

This publication is funded with qualified outer continental shelf oil and gas revenues through the Coastal Impact Assistance Program, U.S. Fish and Wildlife Service, U.S. Department of the Interior.

The views and conclusions contained in this document are those of the authors and should not be interpreted as representing the opinions or policies of the U.S. Government. Mention of trade names or commercial products does not constitute their endorsement by the U.S. Government. 


\section{September 19, 2014}

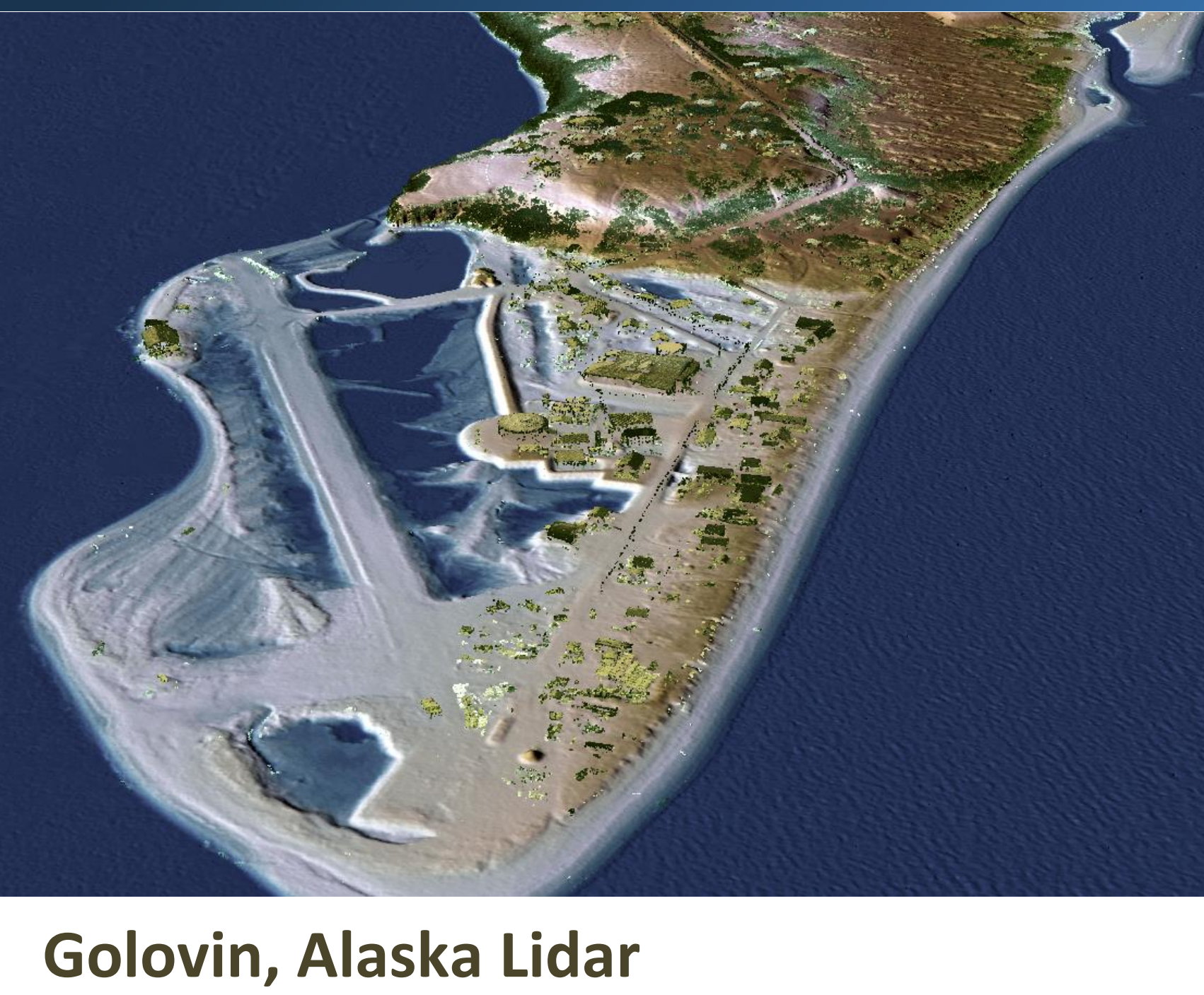

\section{Technical Data Report}

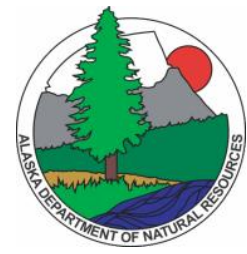

Nicole Kinsman, Coastal Hazards Geologist Alaska Department of Natural Resources, Division of Geological \& Geophysical Surveys 3354 College Road

Fairbanks, Alaska 99709-3707

PH: 907-451-5026

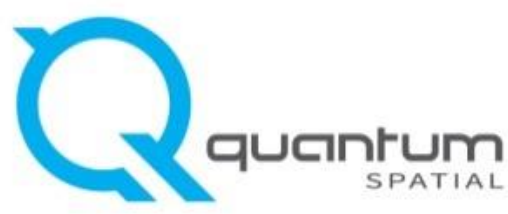

QSI Anchorage Office 2014 Merrill Field Drive Anchorage, AK 99501

PH: 907-272-4495

AMI Reference \#6140809 



\section{TABLE OF CONTENTS}

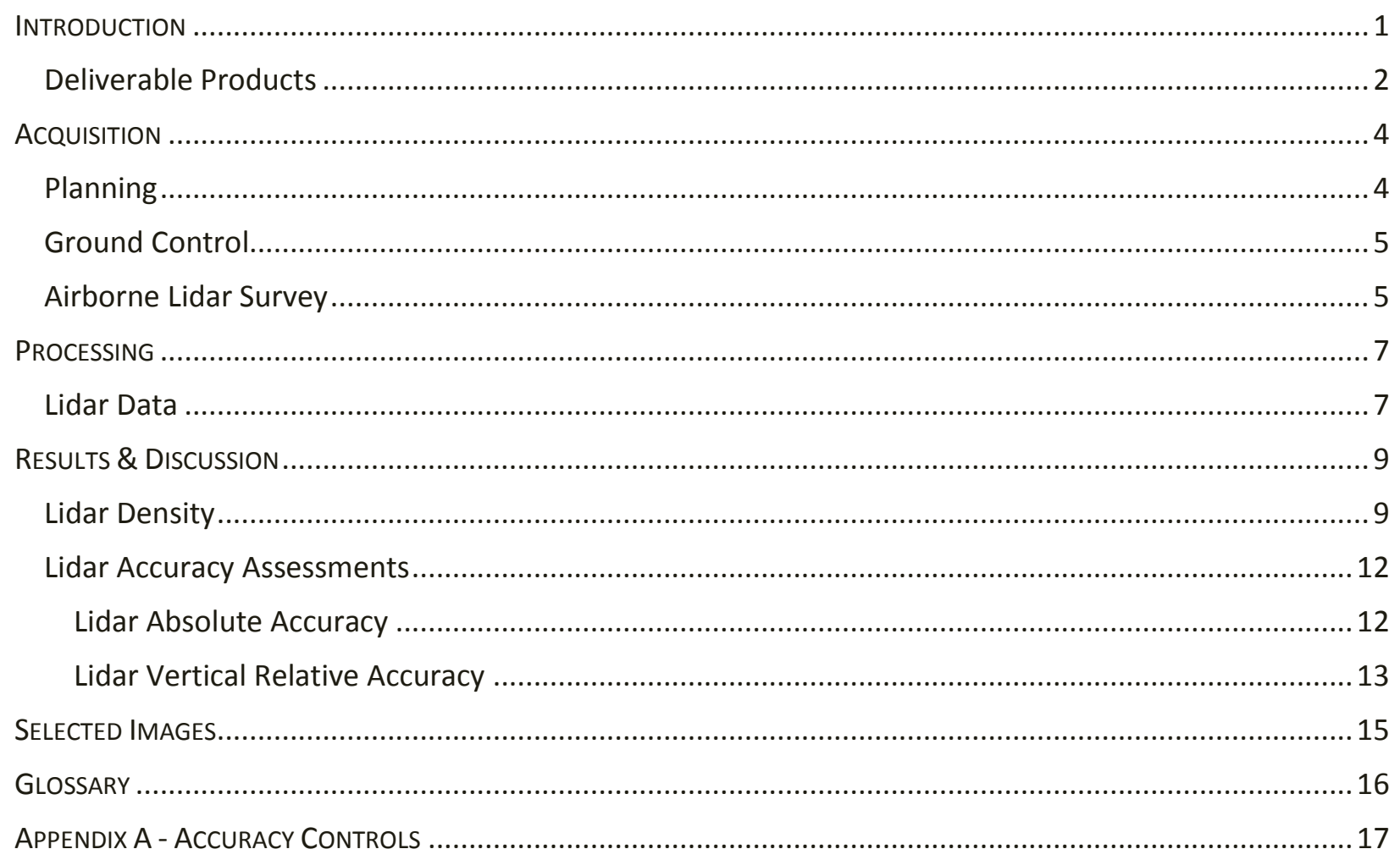

Cover Photo: A view looking northeast over Golovin, Alaska. The image was created from the gridded lidar surface colored by elevation and overlaid with the above ground lidar point cloud. 



\section{INTRODUCTION}

This image shows a view looking northeast over an airstrip in Golovin, Alaska. The image was created from the gridded lidar surface colored by elevation and overlaid with the lidar point cloud.

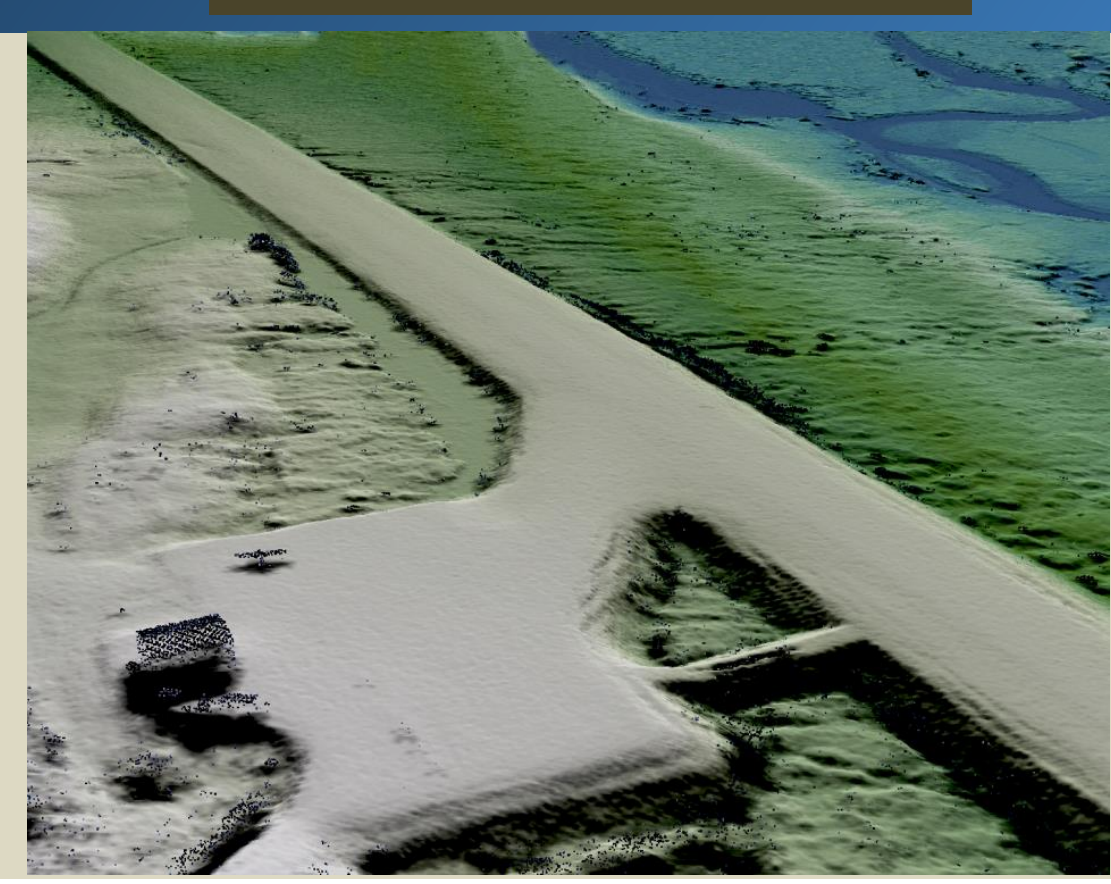

In August 2014, Quantum Spatial (QSI, previously Aerometric), was contracted by the Alaska Department of Natural Resources, Division of Geological and Geophysical Surveys (AKDGGS) to process Light Detection and Ranging (lidar) data previously collected in the fall of 2013 for the town of Golovin, Alaska. AKDGGS' area of interest (AOI) was larger in extent than the previous AOI for which the data was acquired. This resulted in small but unavoidable data gaps along the northern boundary and lower point densities in the eastern section of the AOI not specifically targeted during the acquisition. All discernible laser returns from the fall 2013 acquisition were processed to aid AKDGGS in assessing the topographic and geophysical properties of the study area to support storm monitoring.

This report accompanies the delivered Golovin lidar data and documents contract specifications, data acquisition procedures, processing methods, and analysis of the final dataset including lidar accuracy and density. Acquisition dates and acreage are shown in Table 1, a complete list of contracted deliverables provided to AKDGGS is shown in Table 2, and the project extent is shown in Figure 1.

Table 1: Acquisition dates, acreage, and data types collected on the Golovin site

\begin{tabular}{|c|c|c|c|}
\hline Project Site & Total Acres & Acquisition Dates & Data Type \\
\hline Golovin & 1,050 & 09/05/2013 & Lidar \\
\hline
\end{tabular}




\section{Deliverable Products}

Table 2: Products delivered to AKDGGS for the Golovin site

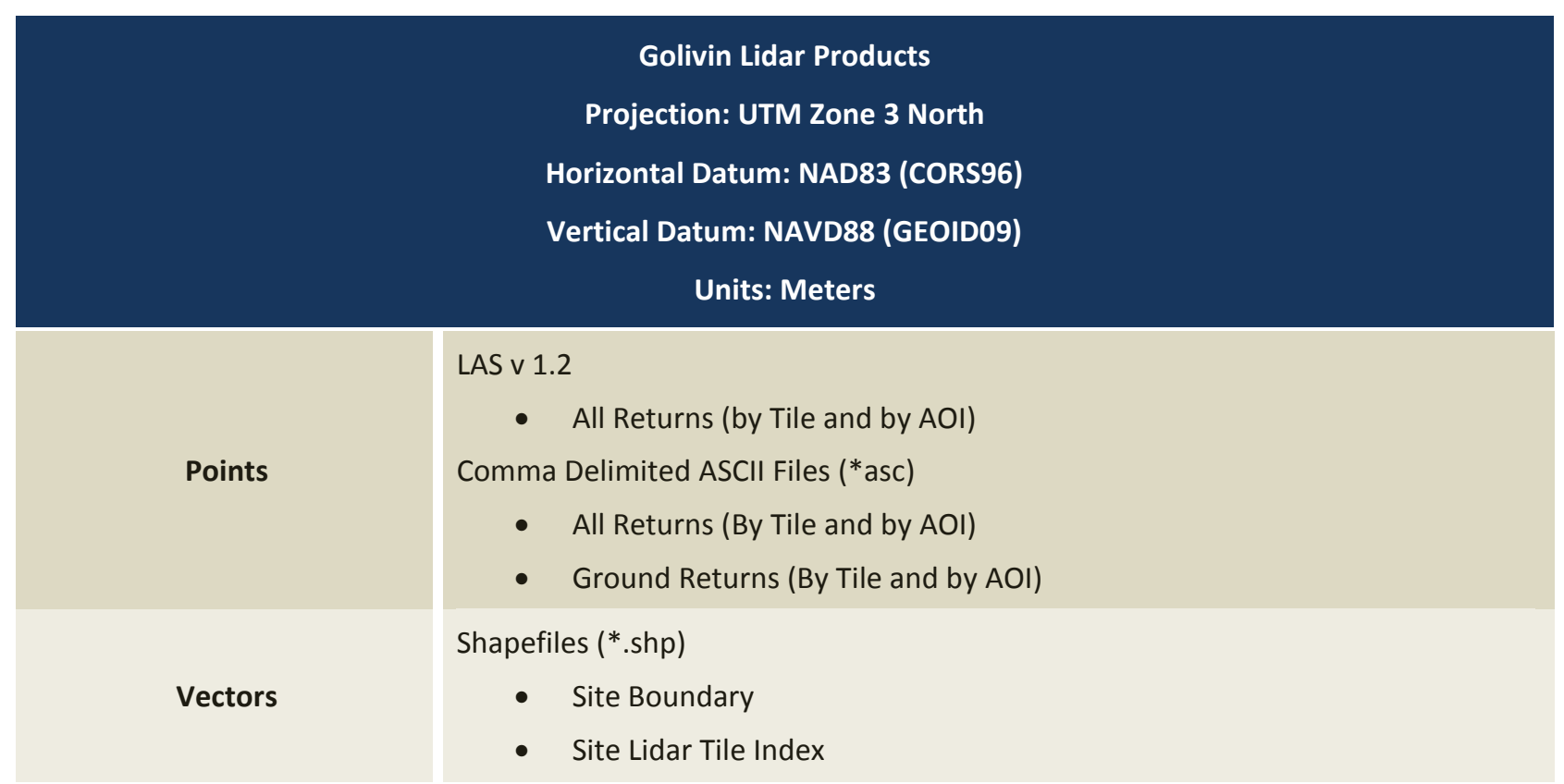




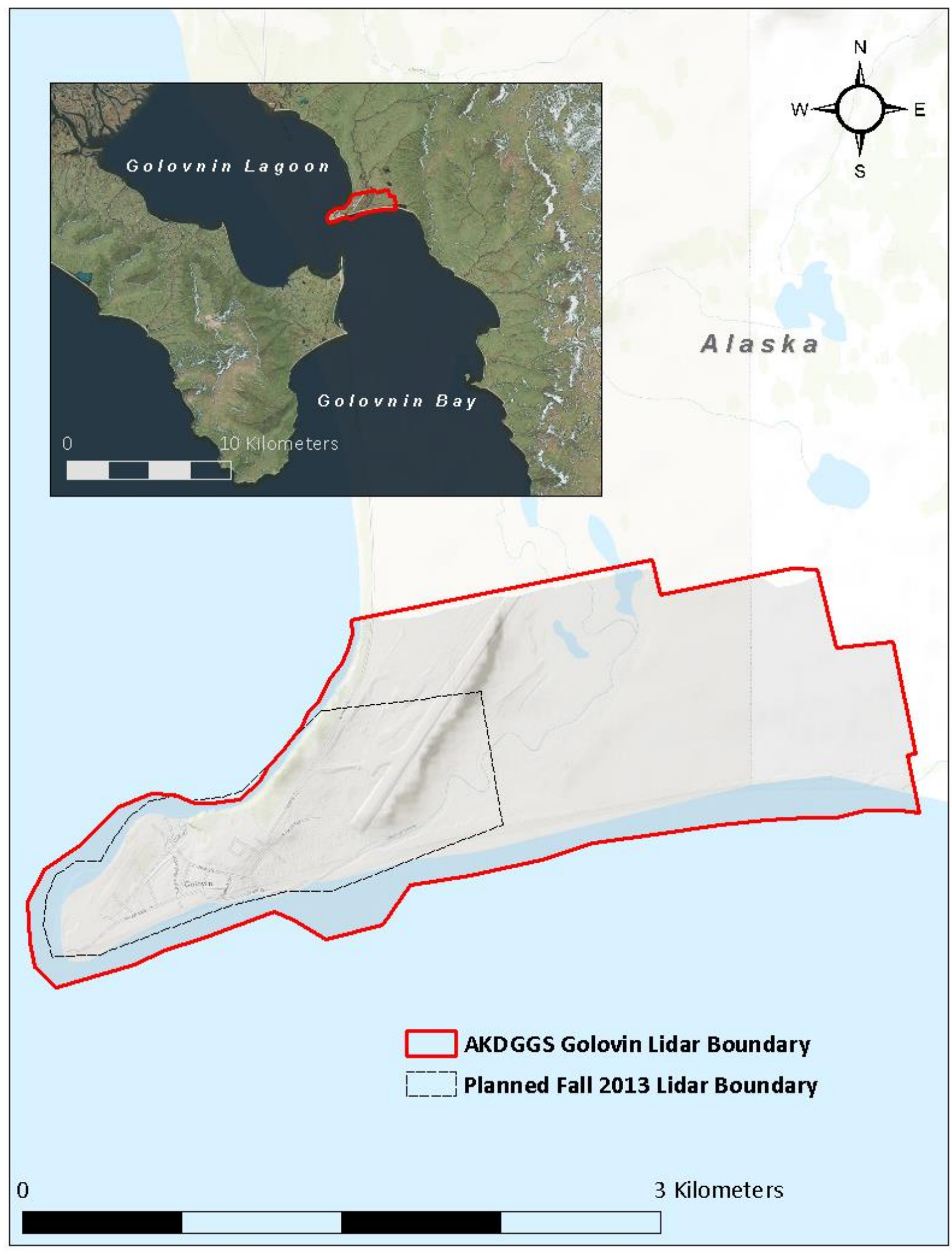

Figure 1: Location map of the Golovin site in Alaska 


\section{ACQUISITION}

QSI's Piper Navajo that was used in lidar acquisition of the Golovin, Alaska project.

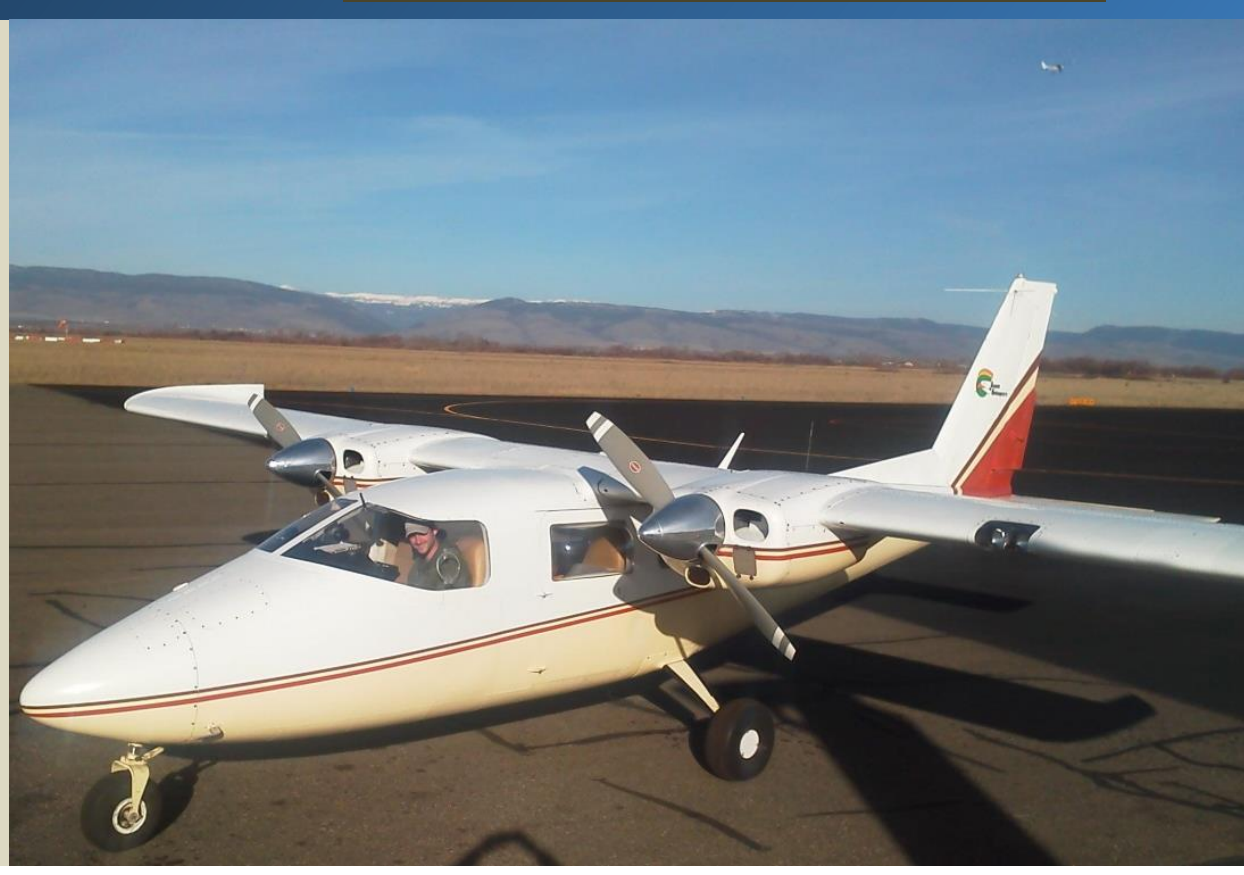

\section{Planning}

In preparation for data collection, the project area was reviewed and a specialized flight plan was developed to ensure complete coverage of the Golovin lidar study area at the target point density of $\geq 4.0$ points $/ \mathrm{m}^{2}$ (0.37 points $\left./ \mathrm{ft}^{2}\right)$. Acquisition parameters including orientation relative to terrain, flight altitude, pulse rate, scan angle, and ground speed were adapted to optimize flight paths and flight times while meeting all contract specifications.

Factors such as satellite constellation availability and weather windows must be considered during the planning stage. Any weather hazards or conditions affecting the flight were continuously monitored due to their potential impact on the daily success of airborne and ground operations. In addition, logistical considerations including private property access and potential air space restrictions were reviewed. 


\section{Ground Control}

Ground control points were provided to QSI by the Alaska Division of Geological and Geophysical Surveys (AKDGGS) and were used to geospatially correct the aircraft positional coordinate data and to perform quality assurance checks on final Lidar data. In total, 17 ground control points were provided, however, 2 outlier points were excluded from the final control dataset.

\section{Airborne Lidar Survey}

The Lidar survey was accomplished using an Optech Gemini system mounted in Piper Navajo. Table 3 summarizes the settings used to yield an average pulse density of $\geq 4$ pulses $/ \mathrm{m}^{2}$ over the Golovin project area. The Optech laser system records up to four range measurements (returns) per pulse. It is not uncommon for some types of surfaces (e.g., dense vegetation or water) to return fewer pulses to the Lidar sensor than the laser originally emitted. The discrepancy between first return and overall delivered density will vary depending on terrain, land cover, and the prevalence of water bodies. All discernible laser returns were processed for the output dataset.

Table 3: Lidar specifications and survey settings

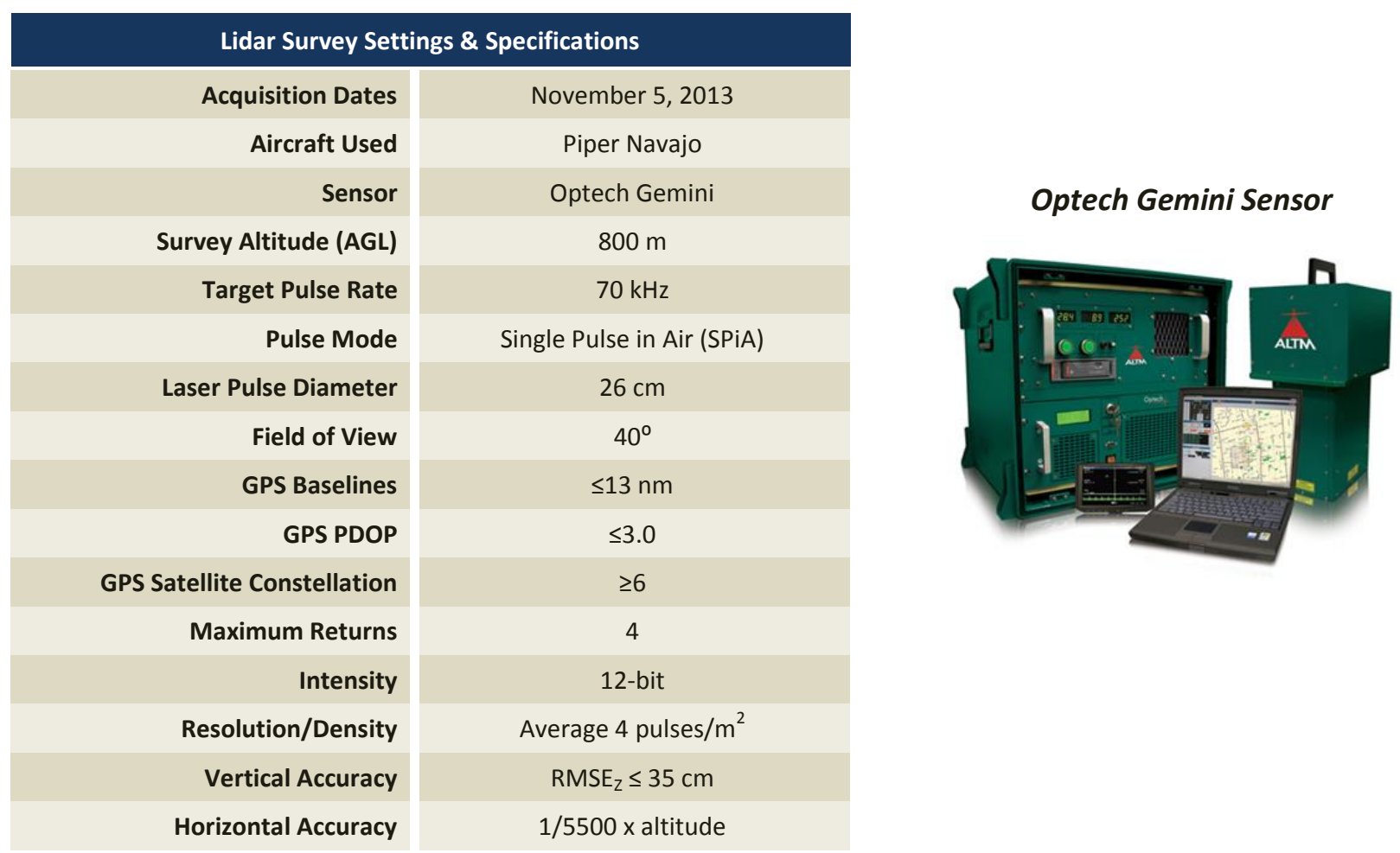

All areas were surveyed with an opposing flight line side-lap of $\geq 50 \%$ ( $\geq 100 \%$ overlap) in order to reduce laser shadowing and increase surface laser painting. To accurately solve for laser point position (geographic coordinates $x, y$ and $z$ ), the positional coordinates of the airborne sensor and the attitude of the aircraft were recorded continuously throughout the Lidar data collection mission. Position of the aircraft was measured twice per second $(2 \mathrm{~Hz})$ by an onboard differential GPS unit, and aircraft attitude was measured 200 times per second $(200 \mathrm{~Hz})$ as pitch, roll and yaw (heading) from an onboard inertial measurement unit (IMU). To allow for post-processing correction and calibration, aircraft and sensor position and attitude data are indexed by GPS time. 


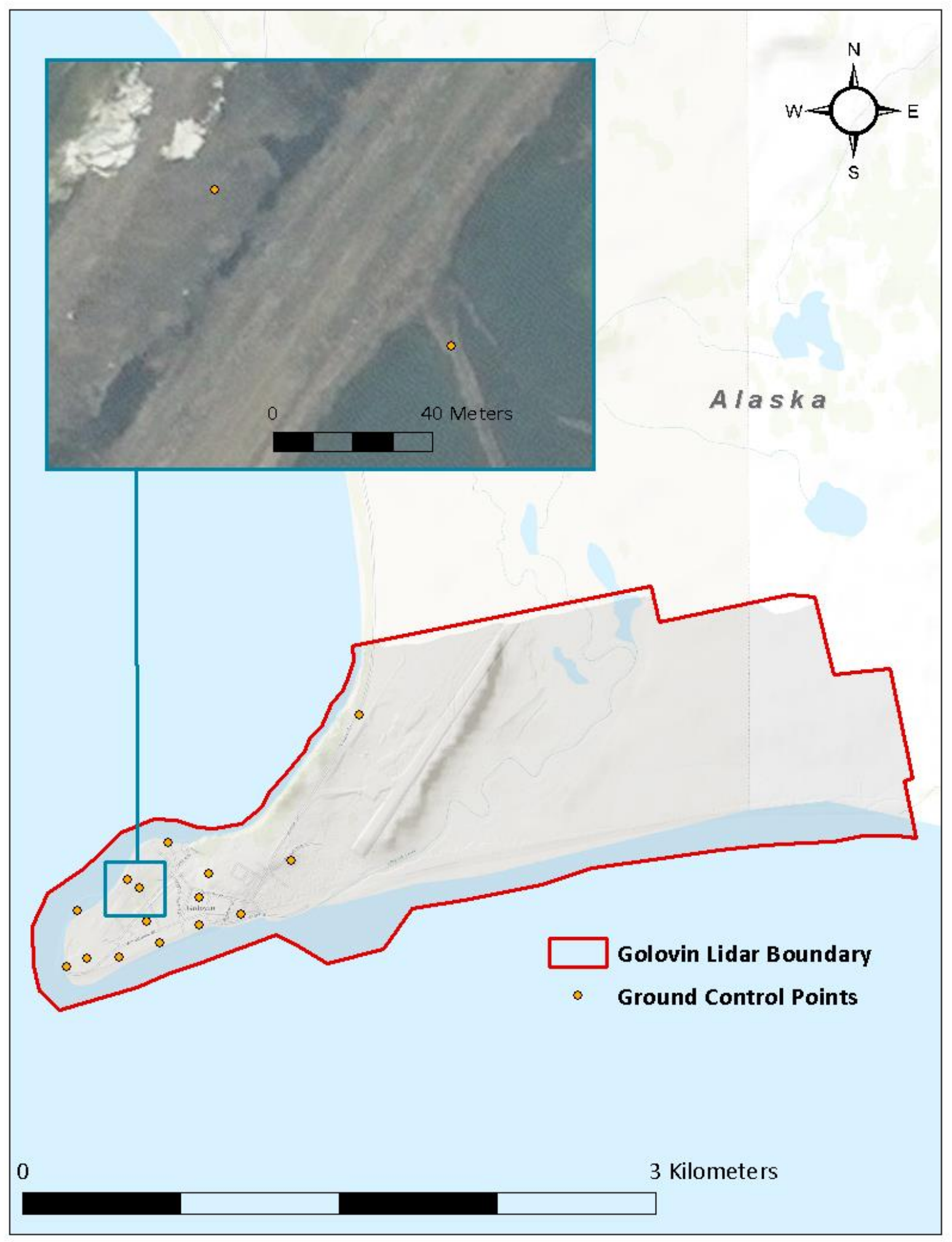

Figure 2: Ground Control location map 
Table 5: Lidar processing workflow

Resolve kinematic corrections for aircraft position data using kinematic

Waypoint GPS v.8.3

aircraft GPS and static ground GPS data.

Global Mapper v.13.0

Develop a smoothed best estimate of trajectory (SBET) file that blends post-processed aircraft position with attitude data. Sensor head position and attitude are calculated throughout the survey. A satellite-only solution

IPAS Pro 2.01.02

using precise point positioning (PPP) techniques refined onboard

TerraPos 2.2.1

measurements of the aircraft position. The SBET data are used extensively for laser point processing.

Calculate laser point position by associating SBET position to each laser point return time, scan angle, intensity, etc. Create raw laser point cloud data for the entire survey in *.las (ASPRS v. 1.2) format. Data are

Optech LMS 2.0 converted to orthometric elevations (NAVD88) by applying a Geoid12 correction.

Import raw laser points into manageable blocks (less than $500 \mathrm{MB}$ ) to perform manual relative accuracy calibration and filter erroneous points. Ground points are then classified for individual flight lines (to be used for relative accuracy testing and calibration).

Using ground classified points per each flight line, the relative accuracy is tested. Automated line-to-line calibrations are then performed for system attitude parameters (pitch, roll, heading), mirror flex (scale) and GPS/IMU drift. Calibrations are calculated on ground classified points from paired flight lines and results are applied to all points in a flight line. Every flight line is used for relative accuracy calibration.

Classify resulting data to ground and other client designated ASPRS classifications (Table 4). Assess statistical absolute accuracy via direct comparisons of ground classified points to ground control data.

TerraScan v.13.008

TerraModeler v.13.002 


\section{RESULTS \& DISCUSSION}

A view of a building above a vegetated hillside which drops off into the Golovnin Lagoon. The image was created from a 3 meter cross section of the lidar points colored by echo.

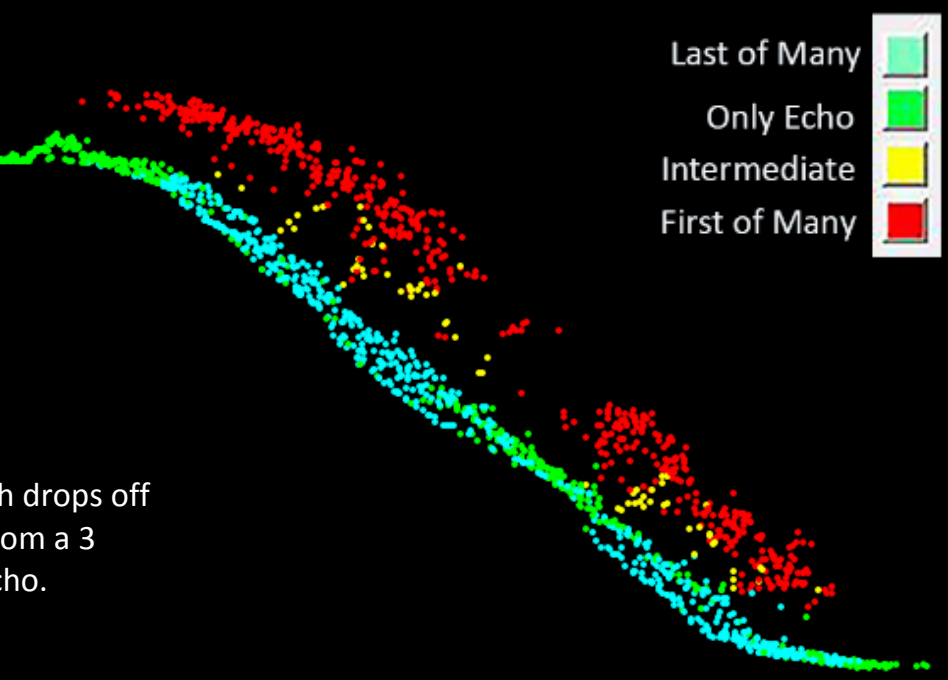

\section{Lidar Density}

The acquisition parameters were designed to acquire an average first-return density of 4 points $/ \mathrm{m}^{2}$ $\left(0.37\right.$ points $\left./ \mathrm{ft}^{2}\right)$. First return density describes the density of pulses emitted from the laser that return at least one echo to the system. Multiple returns from a single pulse were not considered in first return density analysis. Some types of surfaces (e.g., breaks in terrain, water and steep slopes) may have returned fewer pulses than originally emitted by the laser. First returns typically reflect off the highest feature on the landscape within the footprint of the pulse. In forested or urban areas the highest feature could be a tree, building or power line, while in areas of unobstructed ground, the first return will be the only echo and represents the bare earth surface.

The density of ground-classified lidar returns was also analyzed for this project. Terrain character, land cover, and ground surface reflectivity all influenced the density of ground surface returns. In vegetated areas, fewer pulses may penetrate the canopy, resulting in lower ground density.

The average first-return density of lidar data for the Golovin project was 3.61 points $/ \mathrm{m}^{2}$ while the average ground classified density was 1.77 points $/ \mathrm{m}^{2}$ (Table 6). Because the fall 2013 dataset was flown with an alternative area of interest (AOI) that is smaller than the current contracted AOI for the Golovin lidar dataset, the resulting first return density is low in some areas, and single flightline coverage can be found (Figure 5). The statistical and spatial distributions of first return densities and classified ground return densities per $100 \mathrm{~m} \times 100 \mathrm{~m}$ cell are portrayed in Figure 3 through Figure 5. 
Table 6: Average Lidar point densities

\begin{tabular}{|c|c|}
\hline Classification & Point Density \\
\hline First-Return & 3.61 points $/ \mathrm{m}^{2}$ \\
\hline Ground Classified & 1.77 points $/ \mathrm{m}^{2}$ \\
\hline
\end{tabular}

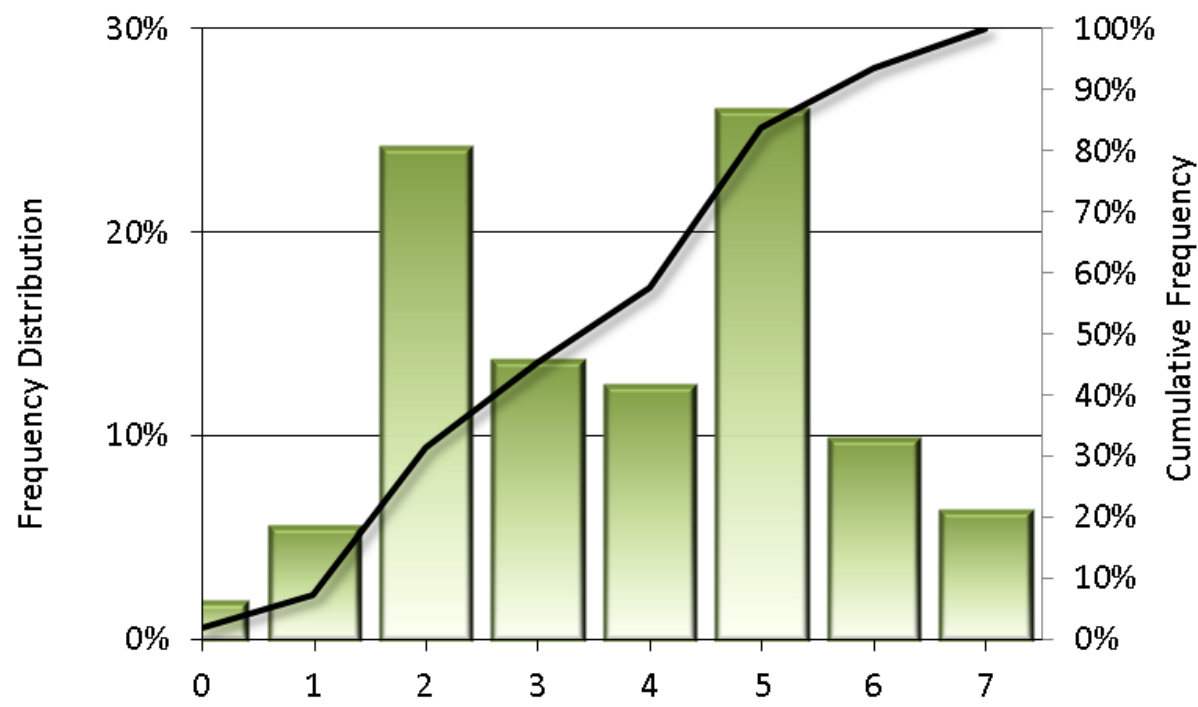

Golovin First Returns (points $/ \mathrm{m}^{2}$ )

Figure 3: Frequency distribution of first return densities per $100 \times 100 \mathrm{~m}$ cell

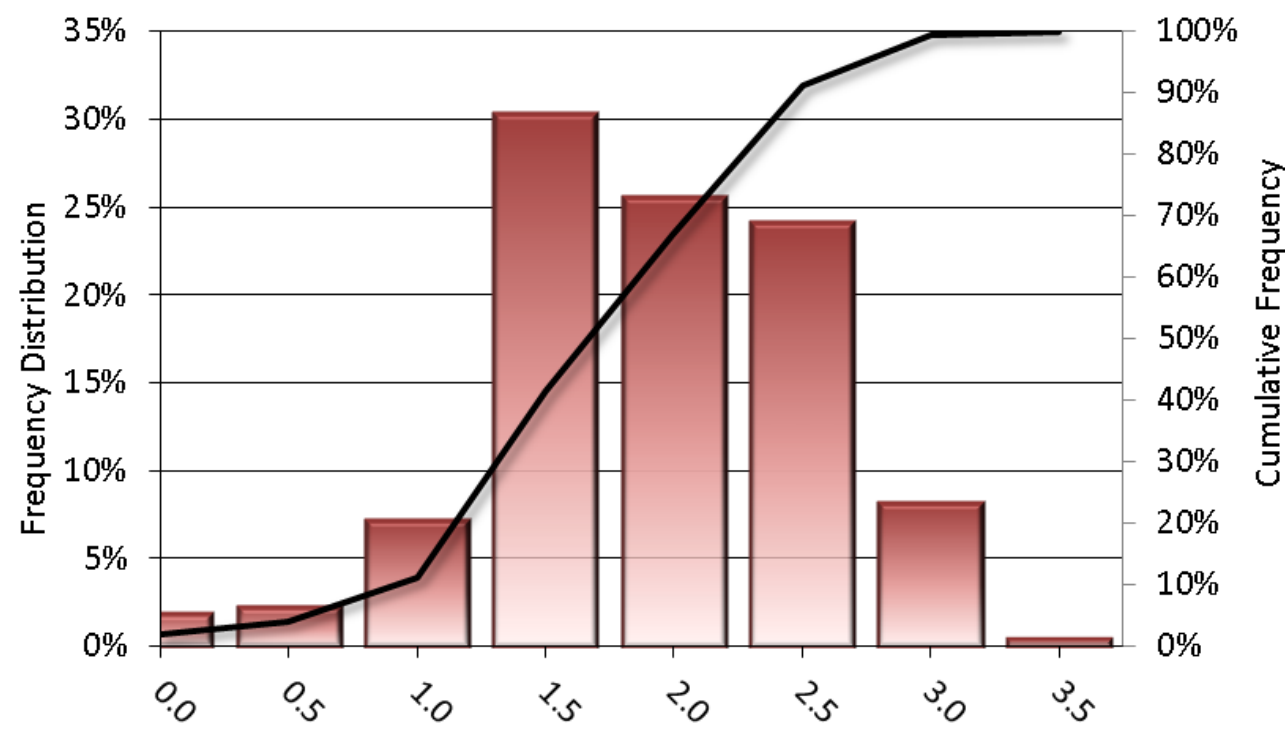

Golovin Ground Classified Returns (points $/ \mathrm{m}^{2}$ )

Figure 4: Frequency distribution of ground return densities per $100 \times 100 \mathrm{~m}$ cell 


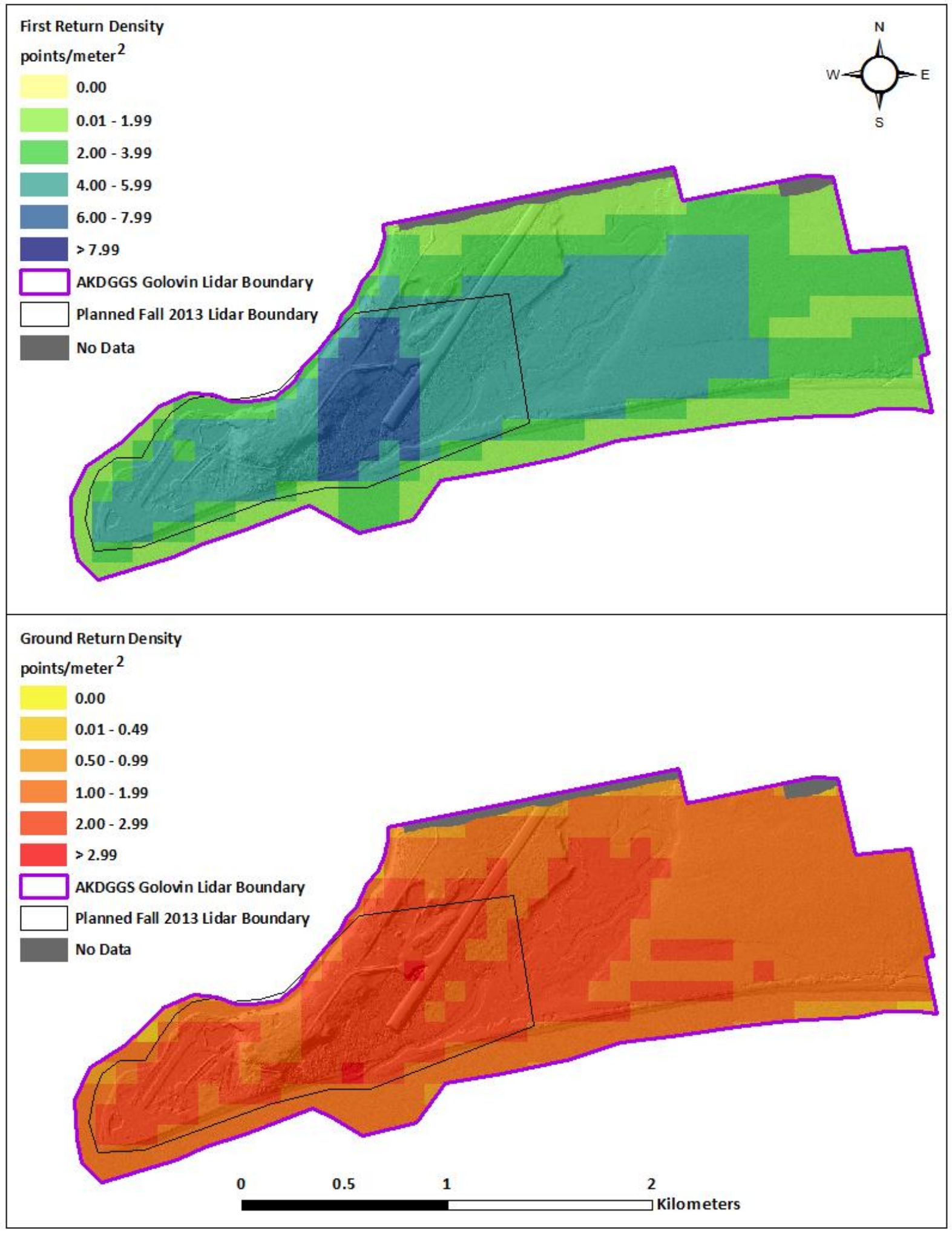

Figure 5: First return and ground density map for the Golovin site (100 m x $100 \mathrm{~m}$ cells) 


\section{Lidar Accuracy Assessments}

The accuracy of the Lidar data collection can be described in terms of absolute accuracy (the consistency of the data with external data sources) and relative accuracy (the consistency of the dataset with itself). See Appendix A for further information on sources of error and operational measures used to improve relative accuracy.

\section{Lidar Absolute Accuracy}

The Optech Gemini system has a stated horizontal accuracy of $1 / 5500$ x altitude. The Golovin lidar data was flown at $800 \mathrm{~m}$ AGL resulting in a horizontal accuracy of $15 \mathrm{~cm}$.

Vertical accuracy was assessed using ground control data provided by the AKDGGS. These control points collected on open, bare earth surfaces with level slope $\left(<20^{\circ}\right)$ are compared to the triangulated surface generated by the lidar points. Absolute accuracy is a measure of the accuracy of lidar point data in open areas where the lidar system has a high probability of measuring the ground surface and is evaluated at the $95 \%$ confidence interval (1.96* RMSE), as shown in Table 7.

The mean and standard deviation (sigma $\sigma$ ) of divergence of the ground surface model from ground survey point coordinates are also considered during accuracy assessment. These statistics assume the error for $\mathrm{x}, \mathrm{y}$ and $\mathrm{z}$ is normally distributed, and therefore the skew and kurtosis of distributions are also considered when evaluating error statistics. For the Golovin survey, 15 ground survey points were collected in total resulting in an average accuracy of-0.003 meters (Figure 6).

Table 7: Vertical Accuracy

\begin{tabular}{|c|c|}
\hline \multicolumn{2}{|c|}{ Absolute Accuracy } \\
\hline Sample & 15 points \\
\hline 1.96*RMSE & $0.210 \mathrm{~m}$ \\
\hline Average & $-0.003 \mathrm{~m}$ \\
\hline Median & $-0.044 m$ \\
\hline RMSE & $0.107 \mathrm{~m}$ \\
\hline 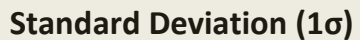 & $0.111 \mathrm{~m}$ \\
\hline
\end{tabular}




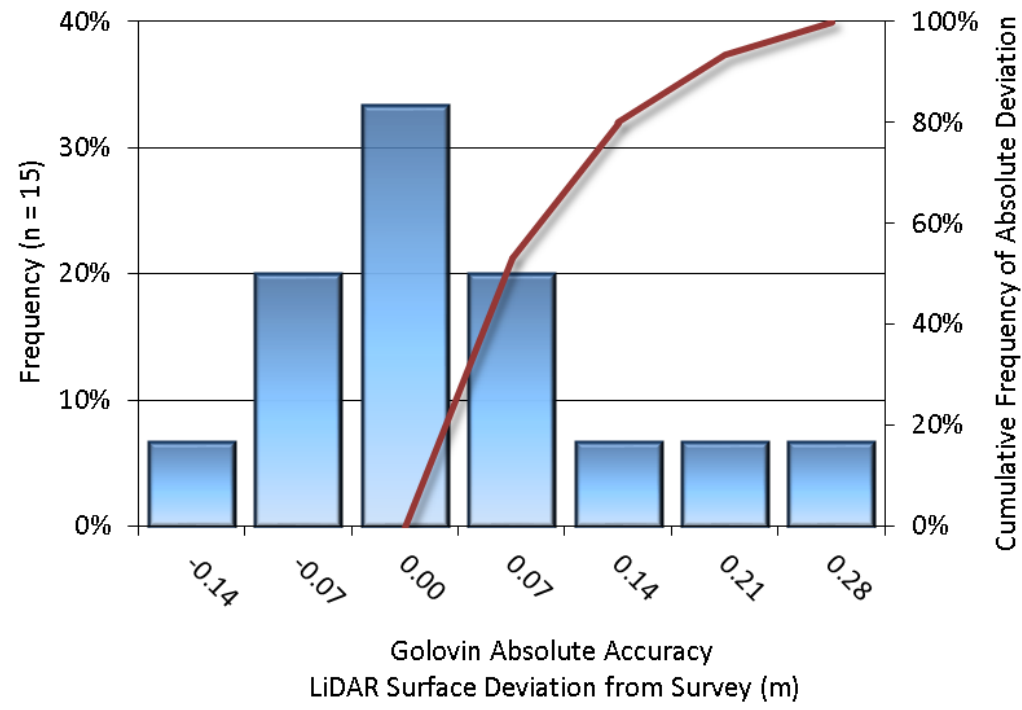

Figure 6: Frequency histogram for lidar surface deviation from client provided ground survey point values

\section{Lidar Relative Vertical Accuracy}

Relative vertical accuracy refers to the internal consistency of the data set as a whole: the ability to place an object in the same location given multiple flight lines, GPS conditions, and aircraft attitudes. When the Lidar system is well calibrated, the swath-to-swath vertical divergence is low ( $<0.10$ meters). The relative vertical accuracy was computed by comparing the ground surface model of each individual flight line with its neighbors in overlapping regions. The average (mean) line to line relative vertical accuracy for the Golovin lidar project was 0.035 meters (Table 8, Figure 7).

Table 8: Relative accuracy

\begin{tabular}{|r|r|}
\hline \multicolumn{2}{|c|}{ Relative Accuracy } \\
\hline Sample & 8 surfaces \\
\hline Average & $0.035 \mathrm{~m}$ \\
\hline Median & $0.035 \mathrm{~m}$ \\
\hline RMSE & $0.035 \mathrm{~m}$ \\
\hline Standard Deviation (1б) & $0.002 \mathrm{~m}$ \\
\hline $1.96 \sigma$ & $0.003 \mathrm{~m}$ \\
\hline
\end{tabular}




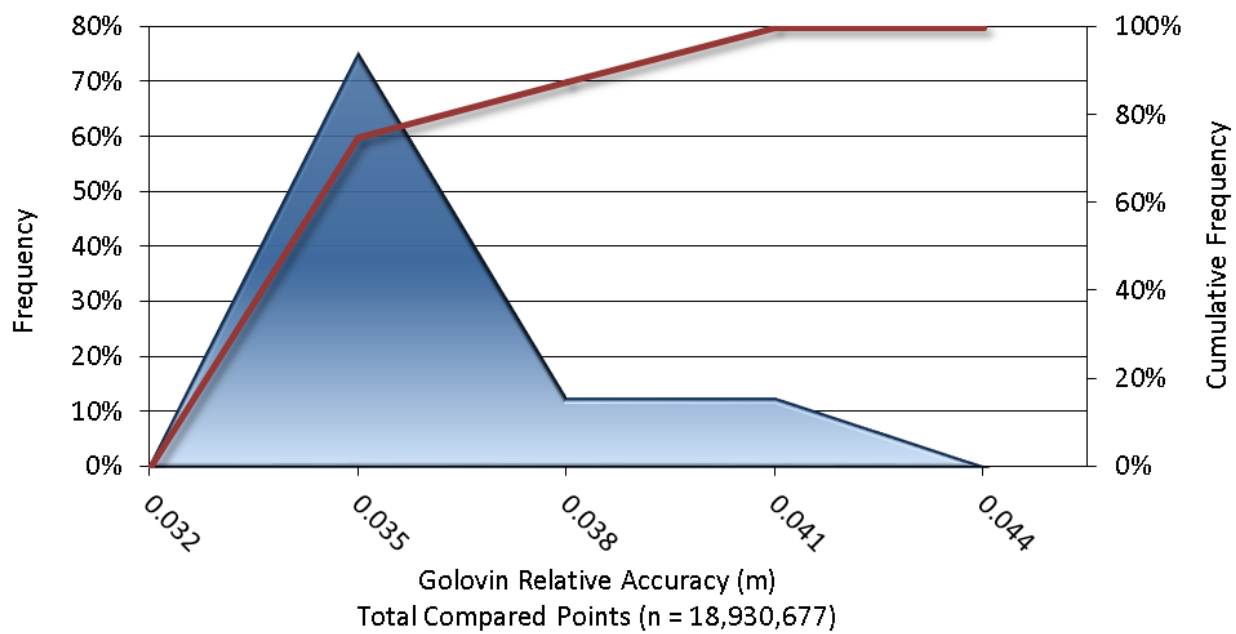

Figure 7: Frequency plot for relative vertical accuracy between flight lines 


\section{Selected IMAges}
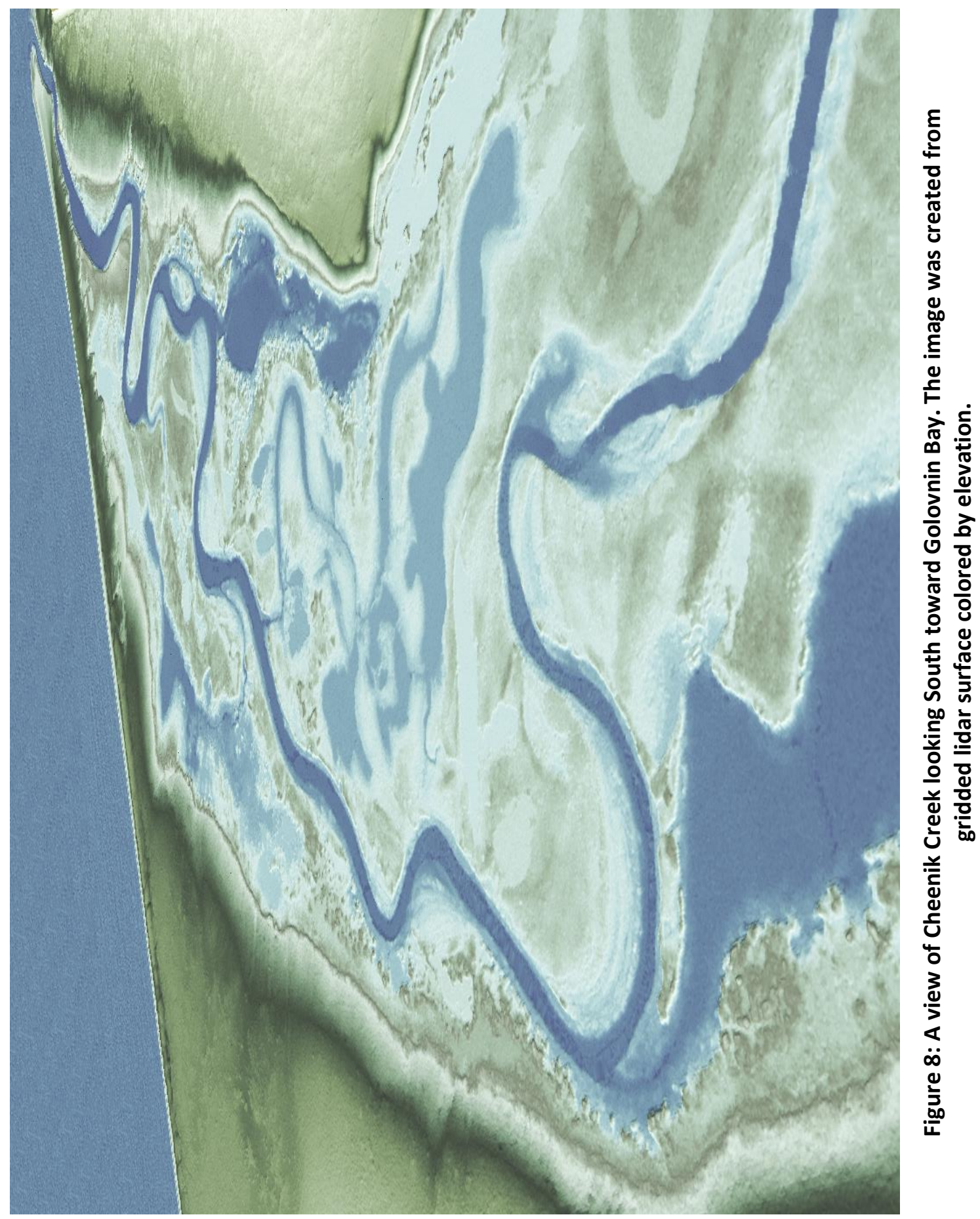


\section{GLOSSARY}

1-sigma $(\sigma)$ Absolute Deviation: Value for which the data are within one standard deviation (approximately $68^{\text {th }}$ percentile) of a normally distributed data set.

1.96 * RMSE Absolute Deviation: Value for which the data are within two standard deviations (approximately $95^{\text {th }}$ percentile) of a normally distributed data set, based on the FGDC standards for Fundamental Vertical Accuracy (FVA) reporting.

Accuracy: The statistical comparison between known (surveyed) points and laser points. Typically measured as the standard deviation (sigma $\sigma$ ) and root mean square error (RMSE).

Absolute Accuracy: The vertical accuracy of LiDAR data is described as the mean and standard deviation (sigma $\sigma$ ) of divergence of lidar point coordinates from ground survey point coordinates. To provide a sense of the model predictive power of the dataset, the root mean square error (RMSE) for vertical accuracy is also provided. These statistics assume the error distributions for $\mathrm{x}, \mathrm{y}$ and $\mathrm{z}$ are normally distributed, and thus we also consider the skew and kurtosis of distributions when evaluating error statistics.

Relative Accuracy: Relative accuracy refers to the internal consistency of the data set; i.e., the ability to place a laser point in the same location over multiple flight lines, GPS conditions and aircraft attitudes. Affected by system attitude offsets, scale and GPS/IMU drift, internal consistency is measured as the divergence between points from different flight lines within an overlapping area. Divergence is most apparent when flight lines are opposing. When the lidar system is well calibrated, the line-to-line divergence is low $(<10 \mathrm{~cm})$.

Root Mean Square Error (RMSE): A statistic used to approximate the difference between real-world points and the lidar points. It is calculated by squaring all the values, then taking the average of the squares and taking the square root of the average.

Data Density: A common measure of lidar resolution, measured as points per square meter.

Digital Elevation Model (DEM): File or database made from surveyed points, containing elevation points over a contiguous area. Digital terrain models (DTM) and digital surface models (DSM) are types of DEMs. DTMs consist solely of the bare earth surface (ground points), while DSMs include information about all surfaces, including vegetation and man-made structures.

Intensity Values: The peak power ratio of the laser return to the emitted laser, calculated as a function of surface reflectivity. Nadir: A single point or locus of points on the surface of the earth directly below a sensor as it progresses along its flight line.

Overlap: The area shared between flight lines, typically measured in percent. $100 \%$ overlap is essential to ensure complete coverage and reduce laser shadows.

Pulse Rate (PR): The rate at which laser pulses are emitted from the sensor; typically measured in thousands of pulses per second $(\mathrm{kHz})$.

Pulse Returns: For every laser pulse emitted, the number of wave forms (i.e., echos) reflected back to the sensor. Portions of the wave form that return first are the highest element in multi-tiered surfaces such as vegetation. Portions of the wave form that return last are the lowest element in multi-tiered surfaces.

Real-Time Kinematic (RTK) Survey: A type of surveying conducted with a GPS base station deployed over a known monument with a radio connection to a GPS rover. Both the base station and rover receive differential GPS data and the baseline correction is solved between the two. This type of ground survey is accurate to $1.5 \mathrm{~cm}$ or less.

Post-Processed Kinematic (PPK) Survey: GPS surveying is conducted with a GPS rover collecting concurrently with a GPS base station set up over a known monument. Differential corrections and precisions for the GNSS baselines are computed and applied after the fact during processing. This type of ground survey is accurate to $1.5 \mathrm{~cm}$ or less.

Scan Angle: The angle from nadir to the edge of the scan, measured in degrees. Laser point accuracy typically decreases as scan angles increase.

Native Lidar Density: The number of pulses emitted by the lidar system, commonly expressed as pulses per square meter. 


\section{APPENDIX A - ACCURACY CONTROLS}

\section{Relative Accuracy Calibration Methodology:}

Manual System Calibration: Calibration procedures for each mission require solving geometric relationships that relate measured swath-to-swath deviations to misalignments of system attitude parameters. Corrected scale, pitch, roll and heading offsets were calculated and applied to resolve misalignments. The raw divergence between lines was computed after the manual calibration was completed and reported for each survey area.

Automated Attitude Calibration: All data were tested and calibrated using TerraMatch automated sampling routines. Ground points were classified for each individual flight line and used for line-to-line testing. System misalignment offsets (pitch, roll and heading) and scale were solved for each individual mission and applied to respective mission datasets. The data from each mission were then blended when imported together to form the entire area of interest.

Automated Z Calibration: Ground points per line were used to calculate the vertical divergence between lines caused by vertical GPS drift. Automated Z calibration was the final step employed for relative accuracy calibration.

\section{LiDAR accuracy error sources and solutions:}

\begin{tabular}{|l|c|c|}
\hline \multicolumn{1}{|c|}{ Type of Error } & Source & Post Processing Solution \\
\hline GPS & Long Base Lines & None \\
\hline (Static/Kinematic) & Poor Satellite Constellation & None \\
\hline Relative Accuracy & Poor Antenna Visibility & Reduce Visibility Mask \\
\hline \multirow{2}{*}{ Laser Noise } & Poor System Calibration & Recalibrate IMU and sensor offsets/settings \\
\hline & Inaccurate System & None \\
\hline & Poor Laser Timing & None \\
\hline & Poor Laser Reception & None \\
\hline
\end{tabular}

\section{Operational measures taken to improve relative accuracy:}

Low Flight Altitude: Terrain following was employed to maintain a constant above ground level (AGL). Laser horizontal errors are a function of flight altitude above ground (about $1 / 3000^{\text {th }} \mathrm{AGL}$ flight altitude).

Focus Laser Power at narrow beam footprint: A laser return must be received by the system above a power threshold to accurately record a measurement. The strength of the laser return (i.e., intensity) is a function of laser emission power, laser footprint, flight altitude and the reflectivity of the target. While surface reflectivity cannot be controlled, laser power can be increased and low flight altitudes can be maintained.

Reduced Scan Angle: Edge-of-scan data can become inaccurate. The scan angle was reduced to a maximum of $\pm 20^{\circ}$ from nadir, creating a narrow swath width and greatly reducing laser shadows from trees and buildings.

Quality GPS: Flights took place during optimal GPS conditions (e.g., 6 or more satellites and PDOP [Position Dilution of Precision] less than 3.0). Before each flight, the PDOP was determined for the survey day. During all flight times, a dual frequency DGPS base station recording at 1 second epochs was utilized and a maximum baseline length between the aircraft and the control points was less than $13 \mathrm{~nm}$ at all times.

Ground Survey: Ground survey point accuracy ( $<1.5 \mathrm{~cm}$ RMSE) occurs during optimal PDOP ranges and targets a minimal baseline distance of 4 miles between GPS rover and base. Robust statistics are, in part, a function of sample size (n) and distribution. Ground survey points are distributed to the extent possible throughout multiple flight lines and across the survey area.

50\% Side-Lap (100\% Overlap): Overlapping areas are optimized for relative accuracy testing. Laser shadowing is minimized to help increase target acquisition from multiple scan angles. Ideally, with a $50 \%$ side-lap, the nadir portion of one flight line coincides with the swath edge portion of overlapping flight lines. A minimum of $50 \%$ side-lap with terrain-followed acquisition prevents data gaps.

Opposing Flight Lines: All overlapping flight lines have opposing directions. Pitch, roll and heading errors are amplified by a factor of two relative to the adjacent flight line(s), making misalignments easier to detect and resolve. 